\title{
Look for New Opportunities in Existing Technologies
}

\section{Leveraging Spatial and Temporal Dimensions to Power Discovery}

Stefano Magistretti ${ }^{1}$, Claudio Dell'Era $^{1}$, Roberto Verganti ${ }^{1}$

${ }^{1}$ School of Management, Politecnico di Milano - Piazza L. da Vinci, 3220133 Milano Italy

This is a post-peer-review, pre-copyedit version of an article published in ResearchTechnology Management Journal. The final authenticated version is available online at: https://doi.org/10.1080/08956308.2020.1686292

Please cite as: Stefano Magistretti, Claudio Dell'Era \& Roberto Verganti (2020) Look for New Opportunities in Existing Technologies, Research-Technology Management, 63:1, 39-48, DOI: $10.1080 / 08956308.2020 .1686292$ 


\title{
Look for New Opportunities in Existing Technologies
}

\section{Leveraging Spatial and Temporal Dimensions to Power Discovery}

\author{
Stefano Magistretti, Claudio Dell'Era, and Roberto Verganti \\ Overview: Several approaches to developing new technologies are available to \\ companies, but few studies explore how the development process can reveal hidden \\ opportunities in existing technologies. This paper investigates the technology \\ development process from the perspective of technology suppliers to consider how they \\ can discover technological opportunities that generate higher value for users. A five-step \\ process can help identify new opportunities during the discovery process, revealing new \\ application fields for the technology.
}

Keywords: Technology development; Technology selection; Open innovation

In today's hypercompetitive environment, firms tend to invest only in technologies that can be quickly launched on the market to create business growth (Amir-Aslani and Negassi 2006). As a result, businesses have looked for ways to harvest new growth from existing technologies. Researchers have identified several technology development methods to unlock latent technological opportunities in existing technology (Chesbrough 2006; Huarng 2010; Liao 2005; Lichtenthaler 2011). The aim of these methods is to foster the development of more valuable applications - that is, solutions that are more profitable than the uses envisioned by the technology's first adopters (Verganti 2009; Trabucchi et al., 2017).

However, this research has focused on generating new value within the dimensions defined by existing products (Danneels and Sethi 2011; Magistretti, Dell'Era, and Messeni-Petruzzelli 2019), leading researchers and practitioners to see technological innovation as a necessary condition for new product development. But existing technology can offer new opportunities as well (Chesbrough 2006). For instance, STMicroelectronics initially integrated its MEMS sensor technology into household appliances, such as washers and dryers, and later introduced it in electronic products, such as the Nintendo Wii and smartphones. This shift was enabled by the company's understanding that MEMS technology offered different opportunities in different markets, from supporting damage prevention in white consumer goods to providing motion recognition capability in electronics (Dell'Era et al., 2017). However, these opportunities are too often missed because innovators do not have a process for identifying and investigating the latent opportunities in existing technologies.

Investigation into how companies repurpose technologies they already have to generate new opportunities and new income is needed to build insight into how these hidden opportunities might be identified and efficiently exploited. By exploring how two technology-developing companies have been able to discover new opportunities and new markets for technologies they have mastered, we show how firms can discover 
opportunity in examining the very essence of the technology. This approach is counterintuitive because it does not rely on improved performance to generate new opportunities; rather, it looks to shift the activity stream in which the technology is applied.

\section{Theoretical Background}

Technology management is the process of planning, managing, and coordinating the development and implementation of a technology (Çetindamar et al. 2009). The literature focuses on three aspects of technology management: technology selection, technology development, and technology integration (Cassiman and Veugelers 2006; Çetindamar et al. 2009; Iansiti 2000; Jepsen, Dell'Era, and Verganti 2014; Krishnan and Bhattacharya 2002; Soukhoroukova, Spann, and Skiera 2012). Technology selection is the first phase of technology management; it is in this phase that a technology is chosen for development from several alternatives (Davoudpour, Rezaee, and Ashrafi 2012). Development follows; in this phase, the opportunities for harvesting value from the technology are explored. In technology integration, the final phase of the process, a new product that leverages the technology is launched in the market (Chang, Hsu, and Tsai 1999; Daim 2013; Iansiti 2000; Kirchberger and Pohl 2016).

This brief overview captures the commonly recognized sequence of technology development. However, as the speed at which the market evolves and competition heightens, the cycle both accelerates and evolves to become more fluid. Often, faced by accelerating cycles and growing competitive pressure, companies resort to technology substitution (Smith 1992; Verganti 2009), simply replacing new technologies for existing solutions to improve functional performance in an effort to win the race to market (Dell'Era et al. 2017). This behavior tends to result from risk aversion and inertia in technology development (Micheli et al. 2012; Ordoobadi 2007); a kind of myopia sets in, causing technology suppliers to focus only on their existing application fields and fail to consider different customer experiences and activity streams where their technology may yield additional value.

Some of this myopia may be a result of focusing too much on the technology itself, rather than exploring how customers interact with it. A number of studies have attempted to show how companies can reduce development costs and time by interacting differently with stakeholders (Lichtenthaler 2003; Thomke 1998; Thomke and Von Hippel 2002). This research shows that companies can better manage technology intelligence and better leverage it to envision different dimensions along which the technology's application may be expanded (Lichtenthaler 2003). Scholars have pointed out how looking at different markets and applications as well as at different technologies in the development process may enable firms to discover new fields where existing technologies can yield value (Magistretti and Dell'Era 2019). Despite this exploration, little work has focused on identifying a process to guide the development of new applications for already marketed technologies.

A wide-ranging development approach, one that escapes the trap of technology substitution, can generate productive technology epiphanies that lead to new revenue streams. A technology epiphany is a sudden revelation of alternative opportunities for the 
application of a technology (Verganti 2009). An epiphany happens when the technology is fully developed and developers suddenly recognize a new opportunity. The opportunity discovered in the epiphany might not require higher performance, but it will require an integration of the technology in a completely new application field. One example of such a reapplication is Kuka's Robocoaster, which uses its industrial robotic technology to create amusement park rides (Danneels and Frattini 2018). The literature around technology epiphanies and how they occur is not vast; effective processes to access such epiphanies and unlock all of the opportunities a technology may offer remain unclear (Verganti 2011a, b; Trabucchi, Talenti, and Buganza 2019). Furthermore, existing studies on the technology development process only recognize the possibility of technology epiphanies and do not explore how they happen.

This study aims to enhance knowledge on the technology development phase from both the researcher and practitioner perspectives by understanding how technological companies can steer technology development to foster more valuable applications and identify latent opportunities and new possibilities for existing technologies.

\section{The Study}

Considering the explorative nature of the study and the complexity of the issue it explores, the researchers deemed a case study methodology (Yin 2003) appropriate. We decided to analyze two cases to enable comparison of results and provide further opportunity to enrich the knowledge on technology development (Dubois and Gadde 2002; Easton 2010; Eisenhardt 1989; Halinen and Törnroos 2005). The sample for the study was selected according to Siggelkow's (2007) guidelines, considering the three aspects of motivation, inspiration, and illustration.

A qualitative study requires a theoretically appropriate selection of cases (Siggelkow 2007). To arrive at such a selection, we started by identifying a sample of technologies that had recently gained significant value in the market as part of consumer products, such as the Nintendo Wii, Kuka Robocoaster, Technogym Kinesis, GoPro, Jawbone UP, and Apple Watch. We then selected those products in which the core technology was developed not for the particular B2C application that had generated so much value but for a broader B2B market. For instance, GoPro and Jawbone were both offered to consumers by companies that had originally developed the proprietary technology at the core of their products for adoption in the B2B market. Ultimately, we selected two technologies, both marketed by U.S. companies, as the focus of our study: the video-encoding technology of Ambarella, and the Motion X technology of Fullpower (Table 1).

\section{---Table 1 near here---}

Data were collected from primary sources, in the form of interviewers with key personnel in the subject companies, and secondary sources, in the form of public documents and videos and press articles. The researchers held four meetings (one exploratory and one confirmatory with each of the two companies); the meetings included a range of people involved in product and technology development, including R\&D managers, vice presidents of Marketing and Business Development, and vice presidents for engineering. Each meeting lasted an average of 2 hours. The interviews followed a semi-structured 
approach; the responses were recorded and transcribed and triangulated with second sources. These sources yielded a good amount of reliable information, including 100 pages of transcripts from approximately 10 hours of interviews.

Two researchers analyzed the data from the transcripts. First, the information was classified chronologically and by topic; topics included the technology development process, the end product, the people involved, and the technology itself. Through this process, and by triangulating with the documentary evidence, we created a reliable chronology of each company's technology evolution. This reconstruction allowed us to analyze the two cases in depth as the companies moved from the initial intended uses of their technologies to more valuable applications.

\section{The Case Companies}

Technologies can offer many different opportunities; developers must search for those outside the company's usual field of focus to capture more value. Our study examined the paths of two companies that, by searching for different opportunities for the technologies on which their core competencies were built, identified different markets that provided new revenue streams. These new markets allowed them to iteratively generate and capture new value from their existing technologies. The evolutionary journeys of these two companies shed light on the path other technology developers might follow to enrich the value of existing technologies by transferring them to other industries.

\section{Ambarella: Video-Encoding Technology}

Ambarella's proprietary video-encoding technology allows a camera to capture, share, and display video content in a faster and qualitatively better way. The firm's expertise derives from its material scientists, who have spent years studying video encoding and how those functions can be embedded on a chip; as a result, Ambarella's research center has developed unique expertise in System-on-Chip (SoC) technology. Ambarella's SoCpowered video-encoding technology is at the heart of a number of radically innovative products, including GoPro cameras.

The company began by producing chips for broadcast cameras and then, over time, moved into consumer-grade action cameras. In other words, it moved from cameras that record someone else's experiences and emotions to cameras that records the user's experience and emotions. The path from commercial to consumer-grade video-encoding technology was not linear. The company had to leverage its growing knowledge of videoencoding technology as it went, addressing different application fields as it did so. As Ambarella's Vice President of Marketing and Business Development explained:

Ambarella at a certain point started designing the chips for handycam cameras. The chips were flexible enough in design and of sufficiently high quality to be used in broadcast head-end equipment. Over time, Ambarella designed specific chips for broadcast applications that were more specialized for this market. This constant tension toward technology development allowed us to approach different markets.

In this way, the company began with broadcast video equipment, then moved into wearable and handheld cameras (the original goal), and then into security, automobile, 
and drone cameras. Ambarella's Vice President of Marketing and Business Development told researchers that the company was continuously searching for new applications for the technology when they identified personal action cameras as an opportunity in the early 2000 s, when it started to dig deeper into the essence of the SoC and video-encoding technology that formed its core technology competency. This process of developing deeper understanding of the technology brought Ambarella to focus further development of the technology on the needs of a new market: the consumer action camera. To achieve the goal of entering that new market, the company invested in R\&D to create a smaller, faster, better-performing video-encoding technology that could be applied in the consumer sector. This new SoC with faster and better-performing video-encoding technology allowed the company to move its application from broadcast handycams to personal action cameras.

Ambarella's first application for its SoC technology was in the video-encoding chips for broadcast infrastructure encoders in 2006, as a steppingstone to its ultimate goal of producing chips for consumer action cameras. This application field, as the interviewee explained, this early move provided the "high guaranteed volume" the company needed "to sustain future development." In 2008, Ambarella moved upstream in the digital content production activity chain, to developing video-encoding chips for consumer and professional recorders. Although the HD video market had suffered disruption from the integration of high-resolution cameras in smartphones, Ambarella did not approach the smartphone application field. Instead, the company targeted a large segment of a more promising application field that required high-performing video-encoding chipsnamely, wearables and action cameras. Later, it developed products for security cameras and drones.

The early excursions into broadcast video encoders and sports, wearable, and handheld cameras allowed Ambarella to explore a new market and move into a radically new activity chain. The company identified that opportunity and then steered technology development to focus on the new application field, rather than focusing on developing new technology or upgrading capabilities.

\section{Fullpower: MotionX}

Fullpower is a leader in developing new technologies and platforms for the Internet of Things and wearables; these applications currently constitute its core business. The company's central product is its MotionX platform, which is comprised of an algorithm and a highly accurate three-axis accelerometer. By understanding the value interactions between sensors and algorithms can have in different contexts, Fullpower was able to foster a move to a new market and a new user for the platform. Fullpower's deep understanding of how data gathered by sensors can be fully exploited provided the foundation for the company's support of Jawbone in developing its Jawbone UP, the first fitness tracker able to measure the quality of sleep; that breakthrough capability rests on a sophisticated algorithm that incorporates MotionX. The addition of the sleep tracker allowed Jawbone to change the context and user base for tracking bracelets, shifting focus from sports tracking to lifestyle tracking. 
As Fullpower's Vice President of Engineering explained, the process of discovery was not easy and linear:

The process that brought us in developing the Jawbone up was really interesting. We started by experimenting the benefit that the interaction between the data gathered from the accelerometer sensor and a good algorithm of interpretation can do. After so, we considered in which industry and context this combination could have played a role. Thus, it was natural to think initially at app for motion sensing and then by digging deeper to something unexplored so fare the more sophisticate sleep monitoring.

The first application released by Fullpower, in 2008, was a mobile application for smartphones called MotionX-Poker, based on a 3-D rendered dice. The app is simple: shaking the iPhone causes five dice to roll and generate numbers on the display. The smartphone's accelerometer captures the shaking motion; a generative algorithm uses that movement to suggest a result for display.

In 2010, Fullpower moved to the mobile application world. Nike+, a partnership with the shoe company, relies on a combination of an algorithm and accelerometers; the app maps and elaborates the data generated by the sensor to provide real-time feedback to athletes. This app represented a further step for Fullpower in developing the MotionX platform for different application fields.

In 2012, the MotionX platform was adopted in a completely different customer experience - the Jawbone UP. With Jawbone, the MotionX platform moved from motion tracking to predicting the REM phases of asleep to wake users up at the optimal moment. This development was the result of a process of continuous evolution of the technology, as the interviewee explained:

Philippe Kahn, our founder and mentor, is a designer who likes to create things, and then it is our role to understand how and where to place the new invention. He envisioned the possibility to create a waking up system, and so by experimenting with the algorithm and the accelerometer we were able to create a powerful platform able to do so. The process was not easy because it required us to consider a completely different context of analysis from body measurement, in Nike+, to brain measurement and prediction with the sleep monitor.

The integration of the MotionX platform into the Jawbone UP bracelet allowed Fullpower to move its technology into a radically new market, revealing a hidden opportunity in the technology.

\section{Discussion}

The two technologies we studied followed similar paths in their introduction to their new markets. First, after the key technology was introduced, each of the companies went on to further develop it for application in different fields. In each case, a deeper consideration of the capabilities of the existing technology (the video-encoding $\mathrm{SoC}$ and the 
sensor+algorithm platform) guided the company in discovering new opportunities in new application fields.

The evidence from the cases shows how technology opportunities can be unlocked by leveraging two dimensions: temporal discovery and spatial discovery (Figure 1).

Temporal discovery aims to reveal hidden opportunities that can be revealed by applying the technology to different activities within the current activity stream. Spatial discovery aims to reveal hidden opportunities that can be accessed by transferring the technology to adjacent customer experiences. In other words, the discovery in the temporal dimension explores different moments of the customer experience within which the technology is currently applied; discovery in the spatial dimension involves shifting to a different customer experience (or activity stream) that offers new applications for the technology - and new opportunities for the company.

\section{---Figure 1 near here---}

In the Ambarella case, development occurred on both dimensions, in two phases (Figure 2). The company first engaged in temporal discovery, which allowed it to shift from broadcasting video encoders to handycam. Handycams were upstream from the broadcasting video encoders in the video-recording customer experience-broadcasting encoders were used at the production moment, and the cameras were used at the real recording moment. Spatial discovery occurred later, when the company moved to an adjacent customer experience - with the incorporation of its chips into GoPro video cameras that allowed consumers to record their own emotion-intensive experiences.

\section{---Figure 2 near here---}

Fullpower followed a similar process in developing its technology (Figure 3). The first adoption of the technology was in smartphones, but the company moved on the temporal dimension, integrating the technology in a downstream activity within the smartphone customer experience. Introducing the technology into the Nike+ system took it from the smartphone to the actual location where the data are generated and collected: the feet. On the spatial dimension, the company shifted to address an adjacent customer experience, moving from tracking activity data to providing data for a more holistic health-oriented application field.

\section{---Figure 3 near here---}

This technology development approach shed lights on how Ambarella and Fullpower discover hidden opportunities for their existing technologies and foster development of more valuable applications for these technologies. The leveraging of the spatial and temporal dimensions to explore opportunities can enrich knowledge about the relevant factors in exploring new opportunities for existing technologies (Buganza et al. 2015; Cooper 2007; Soukhoroukova, Spann, and Skiera 2012; Verganti 2009).

The role of spatial and temporal discovery in uncovering new, high-value opportunities for existing technologies suggests a conceptual framework for pursuing such developments. The framework captures the path taken by the case companies as they 
explored the opportunities offered by their technologies (Figure 4). For both companies, the first step in seeking new opportunities for an existing technology was exploring the technology's uniqueness; in this step, the companies abstractly interpreted the basic features of the existing technology. Understanding what core customer experience the technology enables is essential to grasping the value of the technology. This step was crucial, for example, in Fullpower's case because understanding the power of the accelerometer-algorithm combination allowed the company's engineers to imagine several different possible uses of the technology in the market, from a smartphone app to a sleep monitoring system. That realization followed from the exploration of the system's uniqueness in combining the algorithm and the sensors. Focusing on this uniqueness showed the company different discovery paths that could be leveraged.

\section{---Figure 4 near here---}

The second step is understanding the customer experience, specifically in the context of the technology's unique attributes and current applications. For example, in the Ambarella case, the company recognized that video-encoding technology at that time was only used in the video broadcasting customer experience and not, for example, in the storage of video or in the post-production process.

The understanding built in the second step provides the foundation for temporal discovery - picturing application spaces up- or downstream in the same activity stream where new customer experiences can be enabled by the technology's uniqueness. Ambarella saw an opportunity to embed its technology in other elements of the video production activity stream. Thus, understanding the technology's current position in the activity stream can allow companies to visualize opportunities elsewhere in the activity stream that includes the current application.

At this point, the companies also explored spatial discovery-mapping adjacent application fields that may offer new opportunities. For example, Ambarella focused its technology discovery by mapping all the experiences that its video-encoding chip could enable, from movie making to consumer sports recording.

The process concludes in the fifth step, probing the applications of the technology in the new field, whether that is an up- or downstream field in the same activity stream or an adjacent space. In this step, the solution for the new application is embodied in a final product designed to capture the opportunity - for instance, the inclusion of Ambarella's SoC video-encoding chip into the GoPro.

\section{Lessons Learned}

The two case studies provide four primary insights regarding how the development and adaptation of existing technologies can be guided to uncover more valuable applications and provide access to new opportunities.

1. Discover hidden opportunities by adopting new technology development processes. Finding new applications for existing technology requires exploring both temporally — up and down the activity stream where the technology is currently 
applied — and spatially — in adjacent activity spaces. The technology development process should explicitly engage in this two-dimensional exploration. The five-step process we describe can support managers in this endeavor.

2. Leverage existing latent knowledge to identify spatial and temporal opportunities. Defining the unique attributes of existing technology and exploring spatially and temporally where this unique value is situated can create competitive advantage and unlock new market opportunities.

3. Look at industries and solutions close to your own. The development of the technology can be influenced by both considering the characteristics of the technology itself (leveraging tacit knowledge) and looking at industries and solutions close to the one where the technology is currently applied. This approach can open up new opportunities to develop the technology to meet the needs of multiple markets.

4. Shift from technology supplier to innovation enabler. The conceptual framework we propose may lead suppliers to change their approach, transforming themselves from producers of technologies based on customer requirements to active players in the process of discovering technology opportunities. Indeed, as the cases show, the suppliers-Ambarella and Fullpower-were the enablers of innovation; Go Pro could not have been invented without Ambarella's SoC and Jawbone's sleep tracking required the MotionX capabilities.

\section{Conclusion}

The cases described here are not unique; many other companies followed a similar approach to discover new applications for their core technologies. Notable examples include Kuka's Robocoaster, based on the company's industrial robotics capability (Danneels and Frattini 2018), and STMicroelectronics's MEMS sensor, which made its way into electronics as a result of opportunity identification after the technology's initial introduction in household appliances (Dell'Era et al. 2017). Even as this approach to identifying new opportunities for existing technologies is becoming more popular, however, insights on the management of this process are needed, as well as practical testing. Our conceptual framework suggests a structured method of framing and reframing the technologies attributes and applications to facilitate discovery of hidden opportunities. More exploration is needed to support and expand this framework and to provide guidance for managers dealing with the challenge of exploiting existing technology.

\section{References}

Amir-Aslani, A., and Negassi, S. 2006. Is technology integration the solution to biotechnology's low research and development productivity? Technovation 26(5): 573-582.

Buganza, T., Dell'Era, C., Pellizzoni, E., Trabucchi, D., and Verganti, R. 2015. Unveiling the potentialities provided by new technologies: A process to pursue technology 
epiphanies in the smartphone app industry. Creativity and Innovation Management 24(3): 391-414.

Cassiman, B., and Veugelers, R. 2006. In search of complementarity in innovation strategy: Internal R\&D and external knowledge acquisition. Management Science 52(1): $68-82$.

Çetindamar, D., Wasti, S. N., Ansal, H., and Beyhan, B. 2009. Does technology management research diverge or converge in developing and developed countries? Technovation 29(1): 45-58.

Chang, P. L., Hsu, C. W., and Tsai, C. T. 1999. A stage approach for industrial technology development and implementation: The case of Taiwan's computer industry. Technovation 19(4): 233-241.

Chesbrough, H. 2006. Open Innovation: The New Imperative for Creating and Profiting From Technology. Boston, MA: Harvard Business School Press.

Cooper, R. G. 2007. Managing technology development projects. IEEE Engineering Management Review 35(1): 67-76.

Daim, T. U. 2013. Are formal technology integration processes needed for successful product innovations? International Journal of Innovation Management 17(4): 121.

Danneels, E., and Frattini, F. 2018. Finding applications for technologies beyond the core business. MIT Sloan Management Review 59(3): 73-78.

Danneels, E., and Sethi, R. 2011. New product exploration under environmental turbulence. Organization Science 22(4): 1026-1039.

Davoudpour, H., Rezaee, S., and Ashrafi, M. 2012. Developing a framework for renewable technology portfolio selection: A case study at an R\&D center. Renewable and Sustainable Energy Reviews 16(6): 4291-4297.

Dell'Era, C., Altuna, N., Magistretti, S., and Verganti, R. 2017. Discovering quiescent meanings in technologies: Exploring the design management practices that support the development of technology epiphanies. Technology Analysis and Strategic Management 29(2): 149-166.

Dubois, A., and Gadde, L. E. 2002. Systematic combining: An abductive approach to case research. Journal of Business Research 55(7): 553-560.

Easton, G. 2010. Critical realism in case study research. Industrial Marketing Management 39(1): 118-128.

Eisenhardt, K. M. 1989. Building theories from case study research. Academy of Management Review 14:532-550. 
Halinen, A., and Törnroos, J. A. 2005. Using case methods in the study of contemporary business networks. Journal of Business Research 58(9): 1285-1297.

Huarng, K. H. 2010. Essential research in technology management. Journal of Business Research 63(5): 451-453.

Iansiti, M. 2000. How the incumbent can win: Managing technological transitions in the semiconductor industry. Management Science 46(2): 169-185.

Jepsen, L. B., Dell'Era, C., and Verganti, R. 2014. The contributions of interpreters to the development of radical innovations of meanings: The role of "pioneering projects" in the sustainable buildings industry. R\&D Management 44(1): 1-17.

Kirchberger, M. A., and Pohl, L. 2016. Technology commercialization: A literature review of success factors and antecedents across different contexts. The Journal of Technology Transfer 41(5): 1077-1112.

Krishnan, V., and Bhattacharya, S. 2002. Technology selection and commitment in new product development: The role of uncertainty and design flexibility. Management Science 48(3): 313-327.

Liao, S. H. 2005. Technology management methodologies and applications: A literature review from 1995 to 2003. Technovation 25(4), 381-393.

Lichtenthaler, U. 2003. Third-generation management of technology intelligence processes. $R \& D$ Management 334:361-375.

Lichtenthaler, U. 2011. Open innovation: Past research, current debates, and future directions. Academy of Management Perspectives 25:75-93.

Magistretti, S., and Dell'Era, C. 2019. Unveiling opportunities afforded by emerging technologies: Evidences from the drone industry. Technology Analysis \& Strategic Management 31(5): 606-623.

Magistretti, S., Dell'Era, C., and Messeni-Petruzzelli, A. 2019. How intelligent is Watson? Enabling digital transformation through artificial intelligence. Business Horizons. Online In Press, September 25. https://www.sciencedirect.com/science/article/pii/S0007681319301168

Micheli, P., Schoeman, M., Baxter, D., and Goffin, K. 2012. New business models for public-sector innovation: Successful technological innovation for government. Research-Technology Management 55(5): 51-57.

Ordoobadi, S. M. 2007. Opportunity costs of risks in evaluation of advanced technologies. International Journal of Innovation and Technology Management 4(3): 305-321. 
Siggelkow, N. 2007. Persuasion with case studies. Academy of Management Journal 50(1): 20-24.

Smith, C. G. 1992. Understanding technological substitution: Generic types, substitution dynamics, and influence strategies. Journal of Engineering and Technology Management 9(3-4): 279-302.

Soukhoroukova, A., Spann, M., and Skiera, B. 2012. Sourcing, filtering, and evaluating new product ideas: An empirical exploration of the performance of idea markets. Journal of Product Innovation Management 29(1): 100-112.

Thomke, S. 1998. Managing experimentation in the design of new products. Management Science 44(6): 743-762.

Thomke, S., and Von Hippel, E. 2002. Innovators. Harvard Business Review 80(4): 74 81.

Trabucchi, D., Pellizzoni, E., Buganza, T., and Verganti, R. 2017. Interplay between technology and meaning: How music majors reacted?. Creativity and Innovation Management, 26(4), 327-338.

Trabucchi, D., Talenti, L., and Buganza, T. 2019. How do Big Bang Disruptors look like? A business model perspective. Technological Forecasting and Social Change, 141, 330-340.

Verganti, R. 2009. Design Driven Innovation: Changing the Rules of Competition by Radically Innovating What Things Mean. Boston, MA: Harvard Business School Press.

Verganti, R. 2011a. Designing breakthrough products. Harvard Business Review 89(10): 114-120. https://hbr.org/2011/10/designing-breakthrough-products

Verganti, R. 2011b. Radical design and technology epiphanies: A new focus for research on design management. Journal of Product Innovation Management 28(3): 384388.

Yin, R.K. 2003. Case Study Research: Design and Methods. Thousand Oaks, CA: Sage. 
Table 1.-Case companies and their technologies

\begin{tabular}{|c|c|c|c|}
\hline Company & Technology & Description & Applications \\
\hline Ambarella & $\begin{array}{l}\text { Semiconductors } \\
\text { for video } \\
\text { encoding }\end{array}$ & $\begin{array}{l}\text { Ambarella's semiconductors enable capture, sharing, and } \\
\text { display of HD video. Founded in January } 2004 \text { by Fend-Ming } \\
\text { "Fermi" Wang, Les Kohl, John Ju, and Didier LeGall, the } \\
\text { company now provides the best processors available for the } \\
\text { simultaneous capture of HD video and high-resolution still } \\
\text { images. }\end{array}$ & $\begin{array}{l}\text { Video broadcast cameras (2006) } \\
\text { Sports cameras (2008) } \\
\text { Security cameras }(2011) \\
\text { Automotive cameras }(2012) \\
\text { Flying cameras (drones) (2013) }\end{array}$ \\
\hline Fullpower & $\begin{array}{l}\text { Motion X } \\
\text { platform for IoT } \\
\text { applications }\end{array}$ & $\begin{array}{l}\text { Fullpower's MotionX platform enables IoT functions in all } \\
\text { kinds of devices, from smartphones to drones, by integrating } \\
\text { accelerometers with an algorithm that uses the data gathered by } \\
\text { the sensors to advise users on particular behaviors that might } \\
\text { improve the outcomes of focus. Founded in } 2003 \text { in California } \\
\text { by Philippe Kahn, Fullpower developed its MotionX } \\
\text { technology platform over several years. }\end{array}$ & $\begin{array}{l}\text { Smartphones }(2008) \\
\text { GPS navigators }(2009) \\
\text { Fitness wearables }(2012) \\
\text { Smart furniture }(2013) \\
\text { Drones }(2014)\end{array}$ \\
\hline
\end{tabular}




\section{Figure Captions}

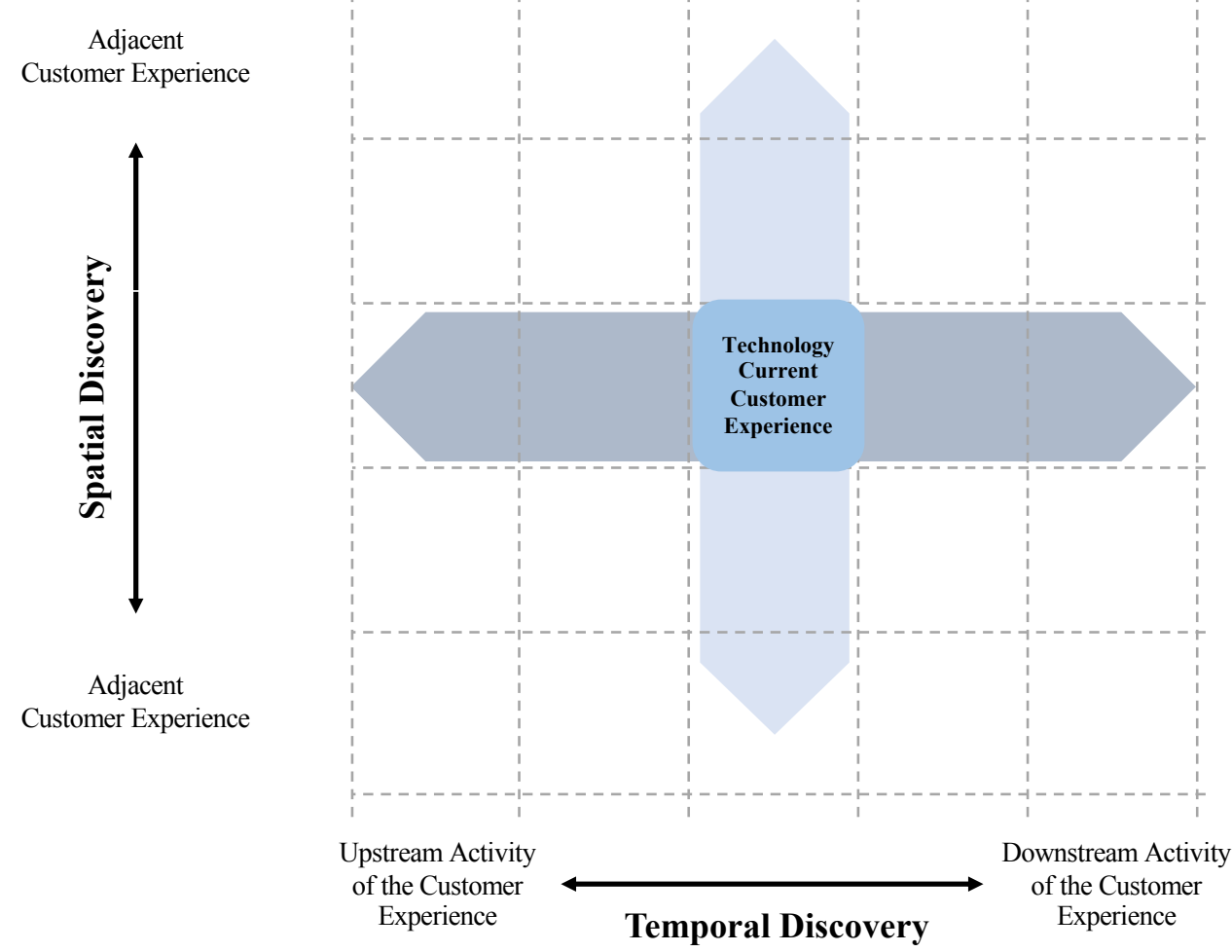

Figure 1.- Temporal vs. spatial discovery 


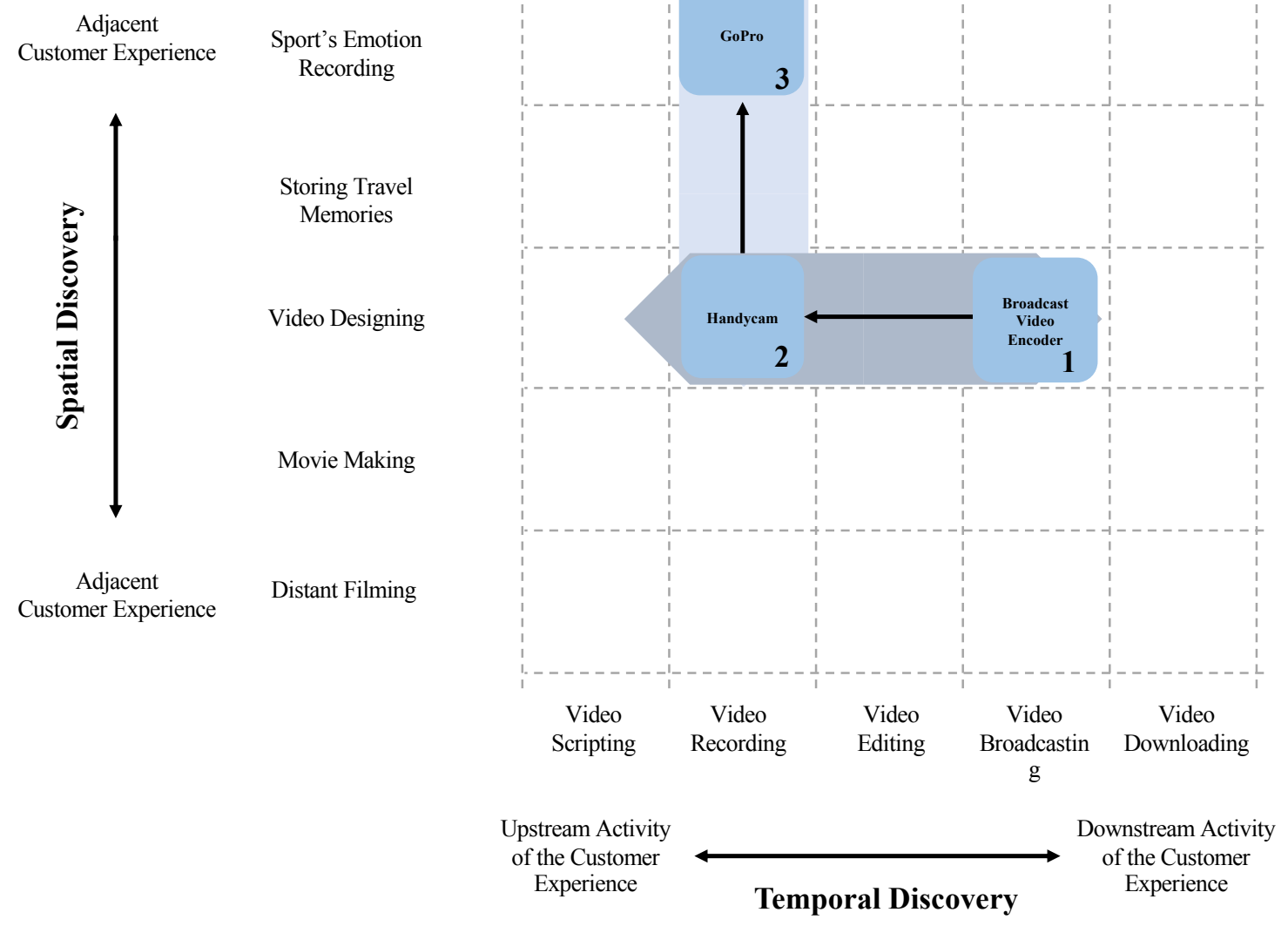

Figure 2.- Temporal and spatial discovery in video-encoding technology (Ambarella) 
Adjacent Customer Experience

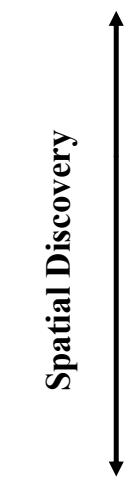

Adjacent

Customer Experience
Wellness programming

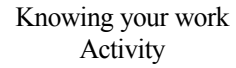

Being aware of your movements

Monitor extreme sport condition

Forecast diseases
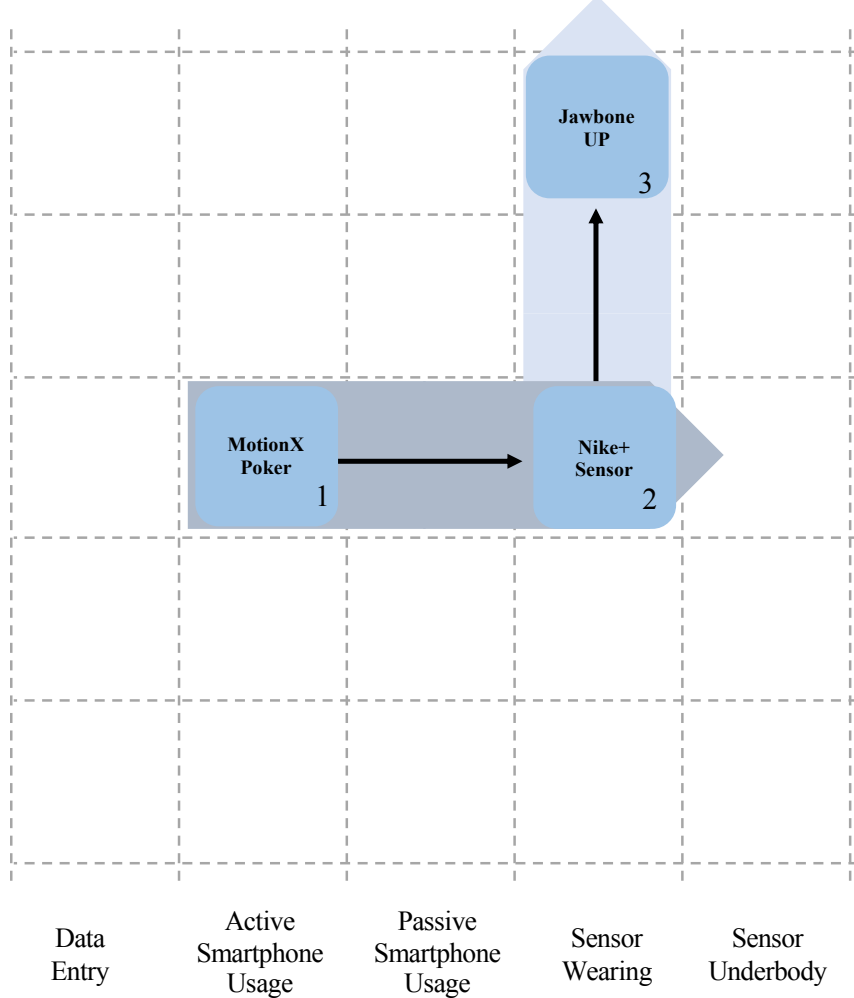

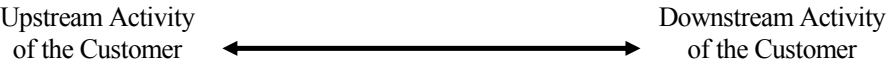
of the Customer
Experience Temporal Discovery $\quad \begin{gathered}\text { of the Custom } \\ \text { Experience }\end{gathered}$

Figure 3.- Temporal and spatial discovery in accelerometer technology (Fullpower)
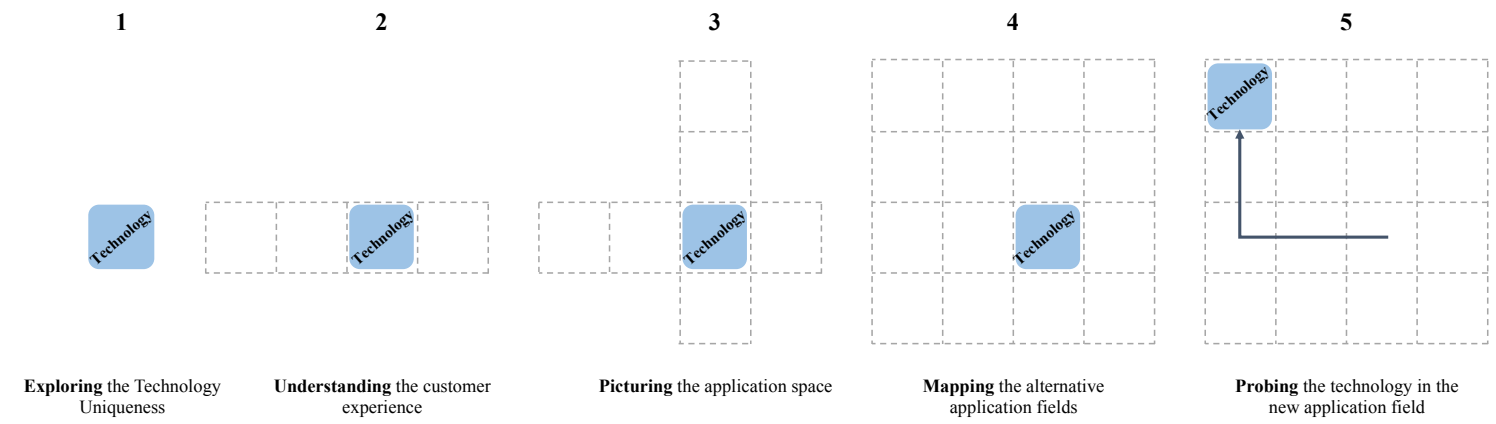
Uniqueness experience application fields

Probing the technology in the new application field

Figure 4.- A five-step process for discovering new opportunities 